\title{
Maternal Effect Mutations: A Novel Cause for Human Reproductive Failure
}

\section{Maternale Effekt-Mutationen: eine neue Ursache für Reproduktionsversagen beim Menschen}

\section{(ㄷ) (2) (1) (5)}

\author{
Author \\ Thomas Eggermann ${ }^{1(\mathbb{D})}$ \\ Institute \\ 1 Institute of Human Genetics, RWTH Aachen University, \\ Aachen, Germany
}

\section{Schlüsselwörter}

subkortikaler maternaler Komplex, Maternal-Effekt-Mutation, Fehlgeburten, Blasenmole, Multi-Locus-Imprintingstörung, Next-Generation-Sequenzierung

Key words

subcortical maternal complex, maternal effect mutation, miscarriages, hydatidiform mole, multilocus imprinting disturbance, next generation sequencing

received 8.12 .2020

accepted after revision $\quad 19.2 .2021$

\section{Bibliografie}

Geburtsh Frauenheilk 2021; 81: 780-788

DOI 10.1055/a-1396-4390

ISSN 0016-5751

(c) 2021. The Author(s). This is an open access article published by Thieme under the terms of the Creative Commons Attribution-NonDerivative-NonCommercial-License, permitting copying and reproduction so long as the original work is given appropriate credit. Contents may not be used for commercial purposes, or adapted, remixed, transformed or built upon. (https://creativecommons.org/licenses/by-nc-nd/4.0/). Georg Thieme Verlag KG, Rüdigerstraße 14,

70469 Stuttgart, Germany

Korrespondenzadresse

Prof. Thomas Eggermann

Institute of Human Genetics

RWTH Aachen University

Pauwelsstraße 30

52074 Aachen, Germany

teggermann@ukaachen.de
ABSTRACT

Genetic alterations significantly contribute to the aetiology of reproductive failure and comprise monogenic, chromosomal and epigenetic disturbances. The implementation of nextgeneration sequencing (NGS) based approaches in research and diagnostics allows the comprehensive analysis of these genetic causes, and the increasing detection rates of genetic mutations causing reproductive complications confirm the potential of the new techniques. Whereas mutations affecting the fetal genome are well known to affect pregnancies and their outcome, the contribution of alterations of the maternal genome was widely unclear. With the recent mainly NGSbased identification of maternal effect variants, a new cause of human reproductive failure has been identified. Maternal effect mutations affect the expression of subcortical maternal complex (SCMC) proteins from the maternal genome, and thereby disturb oocyte maturation and progression of the early embryo. They cause a broad range of reproductive failures and pregnancy complications, including infertility, miscarriages, hydatidiform moles, aneuploidies and imprinting disturbances in the fetus. The identification of women carrying these molecular alterations in SCMC encoding genes is therefore essential for a personalised reproductive and genetic counselling. The diagnostic application of new NGS-based assays allows the comprehensive analysis of these factors, and helps to further decipher these functional links between the factors and their disturbances. A close interdisciplinary collaboration between different disciplines is definitely required to further decipher the complex regulation of early embryo development, and to translate the basic research results into clinical practice.

\section{ZUSAMMENFASSUNG}

Genetische Veränderungen tragen wesentlich zur Ätiologie der Unfruchtbarkeit bei. Sie umfassen monogene Erkrankungen sowie Chromosomenanomalien und epigenetische Veränderungen. Der Einsatz von Next-Generation-Sequenzierung (NGS) in der Forschung und Diagnostik hat eine umfassende Analyse der genetischen Ursachen von Reproduktionsversagen ermöglicht, und die steigende Zahl entdeckter genetischer Mutationen, die zu Schwierigkeiten bei der Reproduktion füh- 
ren, bestätigen das Potenzial dieser neuen Techniken. Es ist zwar bekannt, dass Mutationen, die das fetale Genom beeinflussen, sich auf die Schwangerschaft und das Schwangerschafts-Outcome auswirken, aber inwieweit Änderungen des mütterlichen Genoms sich negativ auswirken, war bislang nicht klar. Die in jüngster Zeit durch NGS ermittelten neuen Maternal-Effekt-Varianten stellen eine neue Ursache für Reproduktionsversagen beim Menschen dar. Maternal-Effekt-Mutationen beeinflussen die Exprimierung von Proteinen des subkortikalen maternalen Komplexes (SCMC) aus dem mütterlichen Genom und verzögern damit die Oozytenreifung bzw. die embryonale Frühentwicklung. Maternal-Effekt-Mutationen sind die Ursache für ein breites Spektrum an reproduktiven Störungen und Schwangerschaftskomplikationen wie Un- fruchtbarkeit, Fehlgeburten, Blasenmolen, Aneuploidien und Störungen der genomischen Prägung des Fetus. Die Identifizierung von Frauen mit molekularen Veränderungen in ihren SCMC-kodierenden Genen ist daher unerlässlich für eine personalisierte reproduktive und genetische Beratung. Der Einsatz neuer NGS-basierter Nachweisverfahren in der Diagnostik erlaubt eine umfassende Analyse solcher Faktoren und hilft bei der Entschlüsselung der Funktionszusammenhänge zwischen diesen Faktoren und der jeweiligen Störung. Eine enge interdisziplinäre Zusammenarbeit zwischen Spezialisten verschiedenster Disziplinen ist gefordert, um die komplexe Regulierung der frühen Embryonalentwicklung weiter zu entschlüsseln und die Ergebnisse dieser Grundlagenforschung in die klinische Praxis umzusetzen.

\section{List of Abbreviations}

$\begin{array}{ll}\text { AZF } & \text { Azoospermia factor gene } \\ \text { BWS } & \text { Beckwith-Wiedemann syndrome } \\ \text { CFTR } & \text { Cystic fibrosis transmembrane regulator gene } \\ \text { CNV } & \text { Copy number variation } \\ \text { GoM } & \text { Gain of methylation } \\ \text { HYDM } & \text { Hydatidiforme mole } \\ \text { IC/IC1 } & \text { Imprinting center/imprinting center 1 } \\ \text { KOS14 } & \text { Kagami-Ogata syndrome } \\ \text { LoM } & \text { Loss of methylation } \\ \text { MLID } & \text { Multilocus imprinting disturbance } \\ \text { NGS } & \text { Next-generation sequencing } \\ \text { POC } & \text { Product of conception } \\ \text { PWS } & \text { Prader-Willi syndrome } \\ \text { SCMC } & \text { Subcortical maternal complex } \\ \text { SNV } & \text { Single nucleotide variant } \\ \text { SRS } & \text { Silver-Russell syndrome } \\ \text { TNDM } & \text { Transient neonatal diabetes mellitus } \\ \text { TS14 } & \text { Temple syndrome } \\ \text { UPD } & \text { Uniparental disomy } \\ \text { WES } & \text { Whole exome sequencing } \\ \text { WGS } & \text { Whole genome sequencing }\end{array}$

\section{Introduction}

Human reproductive failure is defined as the inability to conceive a pregnancy or to carry it out to term, and it has been estimated that only $30 \%$ of all conceptions result in the birth of a child [1]. In fact, many types of reproductive failure can be discriminated, ranging from parental infertility to miscarriages at any time of pregnancy (for review: [2]). Accordingly, the causes of reproductive failure are manifold and comprise urogenital abnormalities, genetic, endocrine and immunological disturbances, as well as exogenic factors.

Genetic mutations significantly contribute to the aetiology of reproductive failure: In infertile men, 4-15\% have genetic defects, among them chromosomal aberrations, cystic fibrosis transmembrane regulator gene (CFTR) mutations and deletions within the azoospermia factor gene (AZF) [3]. In females, numerous genetic alterations with an impact on reproductive processes from ovarian development to embryo implantation have been identified as well (for review: [4]). The prerequisite for the identification of the genetic basis of infertility and reproductive disorders is a comprehensive clinical and diagnostic workup to identify the disturbed biological process as close as possible.

\section{Methodical Progress Contributes to the Identification of (New) Causes of Reproductive Failure}

Within the last decades, a broad range of molecular methods have been implemented in routine diagnostics to identify the molecular basis of congenital disorders, but with the exception of conventional chromosomal analysis they mainly targeted specific monogenetic defects and thereby addressed only specific alterations (e.g. CFTR mutations or AZF deletions). However, the heterogeneous phenotypes and causes of reproductive diseases often make the application of these directed genetic tests difficult, therefore the use of unbiased genomic tests (microarrays, next generation sequencing/NGS) in the diagnostic workup has notably improved the mutation detection rate in molecular diagnostics of male and female infertility and pregnancy loss (for review: $[4,5,6]$ ).

Chromosomal disturbances identified by conventional karyotyping were the first genetic abnormalities which could be causally linked to reproductive failure, like $45, X$ or $47, X X Y$ in infertility. Whereas numerical alterations are easily detectable by this approach, smaller copy number variants $(<5 \mathrm{Mb})$ commonly escape detection. Therefore, molecular karyotyping (microarray analysis: comparative genome hybridisation array or single nucleotide polymorphism arrays [array CGH, SNP array]) has been introduced in diagnostics workup and has increased the detection rates in different reproductive failure cohorts (e.g. [5, 7, 8]). In addition to their contribution to human infertility, chromosomal abnormalities account for up to $50 \%$ of pregnancy losses [9], and mainly comprise numerical aberrations (i.e. trisomies or monosomies). These abnormalities often occur sporadic, but familial chromosomal re- 
arrangements or genetic predispositions can cause recurrent pregnancy losses. For that reason, conventional chromosomal analysis and molecular karyotyping of the products of conception (POC) and/or the parents have been suggested to be included in the diagnostic workup of recurrent pregnancy loss, but are controversially discussed (for review: [7]). In fact, the recently published guidelines of the European Society of Human Reproduction (ESHRE) did not recommend parental and POC karyotyping as a routine diagnostic tool but only for explanatory purposes [10].

A major milestone of unbiased analysis of the whole genome was achieved with the development and diagnostic use of NextGeneration Sequencing (NGS) to target single nucleotide variants (SNVs) and small copy number variants (CNVs): With this approach, the parallel analysis of numerous genes, or even the comprehensive analysis of the whole genome by NGS has become possible, and it is therefore a quantum jump in routine molecular diagnostics. In heterogeneous disorders with hundreds of genes known to cause similar and overlapping phenotypes, these genes can now be analysed within the same run and assessment pipeline.
Additionally, in case of NGS formats addressing the whole exome or the whole genome (WES: whole exome sequencing; WGS: whole genome sequencing), new genetic causes of diseases can be identified (for review: [5]). Additionally, the development of genome mapping technologies will allow to combine the detection of SNVs with structural chromosomal variants and rearrangements [11].

Thus, the capability of genomic NGS is enormous, but in a diagnostic context it should only be applied after estimating the advantages and disadvantages (for review: [12]): Despite the chances to identify even new causes of reproductive failure, the management of incidental findings as well as of genetic variants of unknown significance has to be considered and to be discussed with the advice seeking couple [13]. Furthermore, the rapid implementation of these new molecular tools in the diagnostic settings makes the interpretation of diagnostic data increasingly complex. Nevertheless, the efficient diagnosis of genetically based reproductive failure disorder can contribute to a precise management and helps the advice seeking couple in their self-determined family
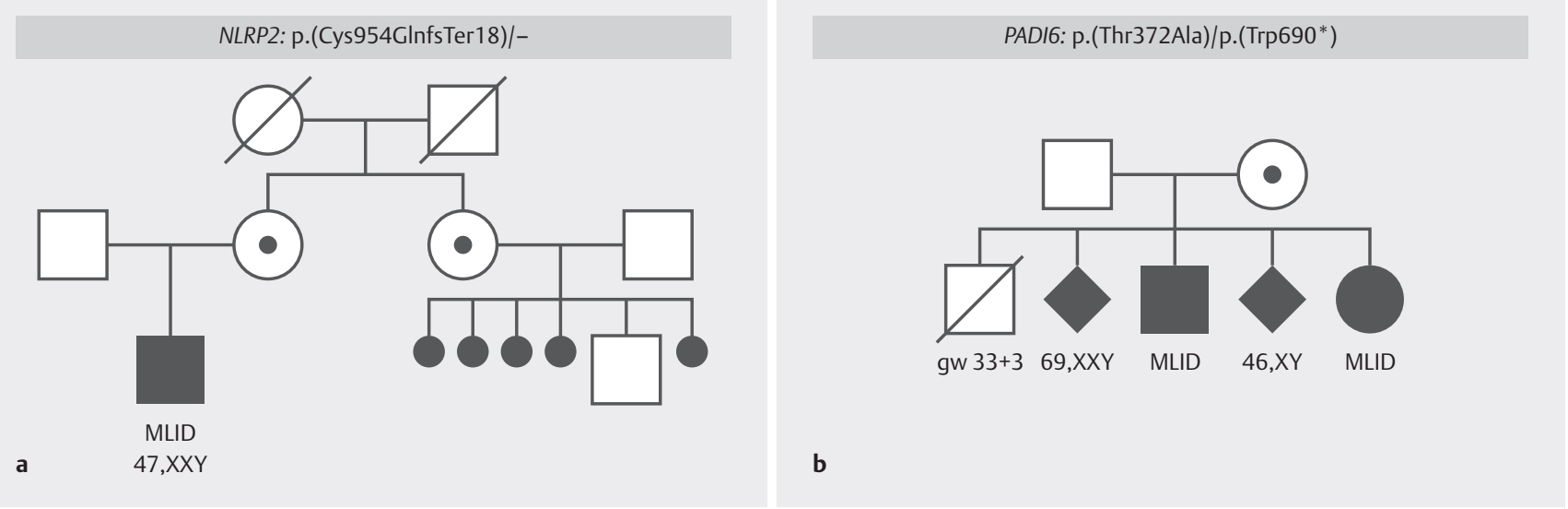

NLRP7: p.(Phe671Glnfs*18)/-

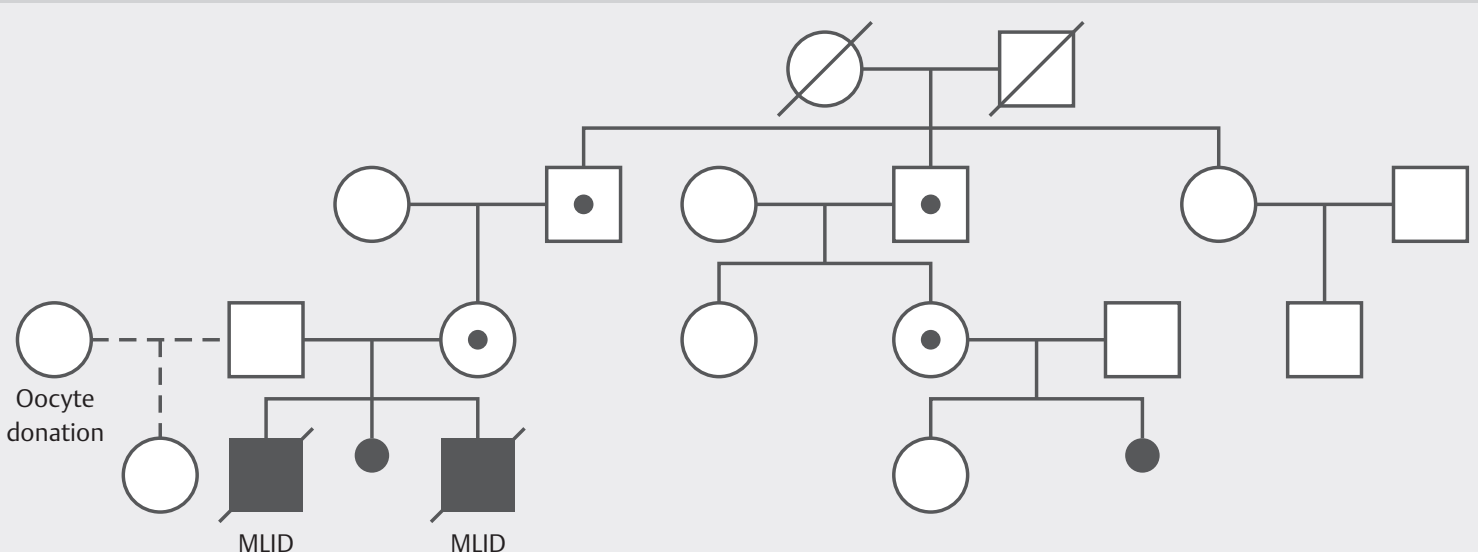

c

MLID

MLID

Fig. 1 Reproductive history in three families with pathogenic variants in SCMC proteins, illustrating the increased occurrence of miscarriages, disturbed imprinting (MLID) and aneuploidy. a The two sisters were heterozygous for a NLPR2 variant, and gave birth to son with Klinefelter syndrome and MLID (family 6 from [14]). b The mother was compound heterozygous for two PADI6 mutations, she experienced several miscarriages and had two children with MLID (from: [15]). c In the third family, two women heterozygous for a NLRP7 variant suffered from miscarriages, but after oocyte donation one sister gave birth to healthy child (from: [16]). 
planning. Furthermore, the identification of a causative (epi)genetic alteration allows the prognosis of recurrence risks for further family members (see pedigrees in $\mathbf{D}$ Fig. $\mathbf{1}$ ) as carriers of pathogenic variants can be identified and reproductive counselling can be offered, where appropriate. Examples are familial chromosomal translocations or maternal effect variants (see below).

However, despite the power of the new comprehensive and unbiased molecular tests, it is noteworthy to mention that the prerequisite of a targeted and efficient genetic test is the comprehensive evaluation of the phenotype (deep phenotyping) and recording of the medical history, which helps to specify the order for genetic testing.

\section{Molecular Causes of Reproductive Failure}

Genetic causes of pregnancy complications and reproductive failure comprise both maternal and fetal determinants. Examples of maternal genetic predispositions for pregnancy loss are mutations in coagulation factors II (F2, Prothrombin) and V (F5; e.g F5 Leiden variant) (for review: $[4,17])$.

On the fetal side, chromosomal, monogenetic and epigenetic disturbances contribute to pregnancy diseases, as these disturbances might affect the function of the placenta, the viability of the fetus or the metabolism of the mother.

Molecular causes for disturbed placental function include chromosomal trisomies, and even in case the fetus shows a normal chromosomal complement (confined placental trisomy) placental dysfunction might cause miscarriages. Additionally, in these cases undetected chromosomal mosaicism in the fetus as well as uniparental disomy with effects on the phenotype have to be considered (for review: [18]).

Molecular alterations of the fetus himself might have a severe impact on his viability, and might result in intrauterine death. In addition to the well-known pathogenic nature of chromosomal aberrations and monogenetic mutations (e.g. trisomies, homozygous FGFR3 mutations), disturbed genomic imprinting is often associated with pregnancy complications and miscarriages.

\section{Genomic Imprinting and its Disturbances}

Disturbed genomic imprinting means the altered expression of imprinted genes which are expressed monoallelically in a parent-oforigin specific manner. This allele-specific expression is mediated by different molecular marks, among them DNA methylation at specific CPG stretches. In these differentially methylated regions (DMRs), specific cytosine residues are methylated on either the maternal or paternal allele, and thereby regulate their neighboured genes. An example is the imprinting center 1 (IC1) in 11 p15.5 with the IGF2 gene. This gene is expressed solely from the paternal allele, whereas the maternal allele is silenced. Mutations therefore only cause aberrant phenotypes in case of paternal inheritance [19]. Imprinted genes are organised in clusters, and until now 12 different imprinting disorders associated with defects of one of these clusters have been identified (for review: [16]). Four types of molecular alterations might affect imprinted genes: copy number variations (CNVs: deletions/duplications), uniparental disomies (UPD), aberrant methylation marks (epimutations), and monogenetic mutations. Whereas CNVs, UPDs and monogenetic mutations represent classical DNA alterations, in epimutations the DNA sequence itself is not affected, but cytosine methylation as its epigenetic marking has either been lost (Loss of Methylation, LoM) on the methylated allele, or the unmethylated allele has become methylated (Gain of Methylation, GoM).

Disturbances of the fine-balanced monoallelic expression of imprinted genes are associated with imprinting disorders which share the aforementioned types of molecular alterations ( $\bullet$ Fig. 2) [20]. The major clinical features of these entities affect growth, metabolism, cognition and behaviour, and an increased risk for tumour development is known for some of them. Twelve imprinting disorders have been defined, each associated with specific imprinted loci. In fact, several of these entities show at first glance a more or less specific phenotype, but there is a clinical overlap between some of them (e.g. Silver-Russell syndrome [SRS] - Temple syndrome [TS14] - Prader-Willi syndrome [PWS]). Additionally, the increasing number of reports on patients with so-called multilocus imprinting disturbances (MLID) illustrates the molecular and clinical overlap in this group of congenital disorders (for review: $[16,21,22])$. As a result, the clinical diagnosis and decision on the molecular testing strategy might be hindered. Due to this clinical overlap and even a mixture of features in MLID patients, it can be assumed that imprinting disorders are under- and misdiagnosed.

Depending on the imprinting disorder and the molecular subtype, first features are detectable prenatally, ranging from intrauterine growth retardation (e.g. in transient neonatal diabetes mellitus [TNDM], SRS, TS14), polyhydramnios (Beckwith-Wiedemann syndrome [BWS], Kagami-Ogata syndrome [KOS14]), abdominal wall defects (BWS, TNDM, KOS14) and placental mesenchymal dysplasia (BWS). In case of BWS, one third of the mothers show large, overstimulation-like ovaries, and they are at an increased risk to develop preeclampsia [23]. Additionally, children with imprinting disorders are often born pre-term.

As a result, prenatal genetic testing for imprinting disorders is often requested in case these clinical features are detected. Prenatal testing might also be indicated in case of genetic constitutions predisposing to imprinting disorders, e.g. chromosomal mosaicism, familial chromosomal rearrangements or familial inheritance of imprinting mutations.

\section{Maternal Effect Genes and Their Role in Early Embryo Progression}

The establishment, maintenance and erasure of DNA methylation in imprinting domains underlies a so-called "life cycle of imprinting" (for review: [24]): The DNA methylation at the imprinting centres (ICs) is erased in primordial germ cells, and then re-established in the gametes. After fertilisation, the paternal and maternal genomes remain widely unmethylated, but the differential methylation patterns of the maternal and paternal ICs are maintained during implantation of the zygote and during lifetime. This temporal, spatial and parent-of-origin regulation of imprint marking is regulated by a large number of factors, and in many parts it is not fully understood. 


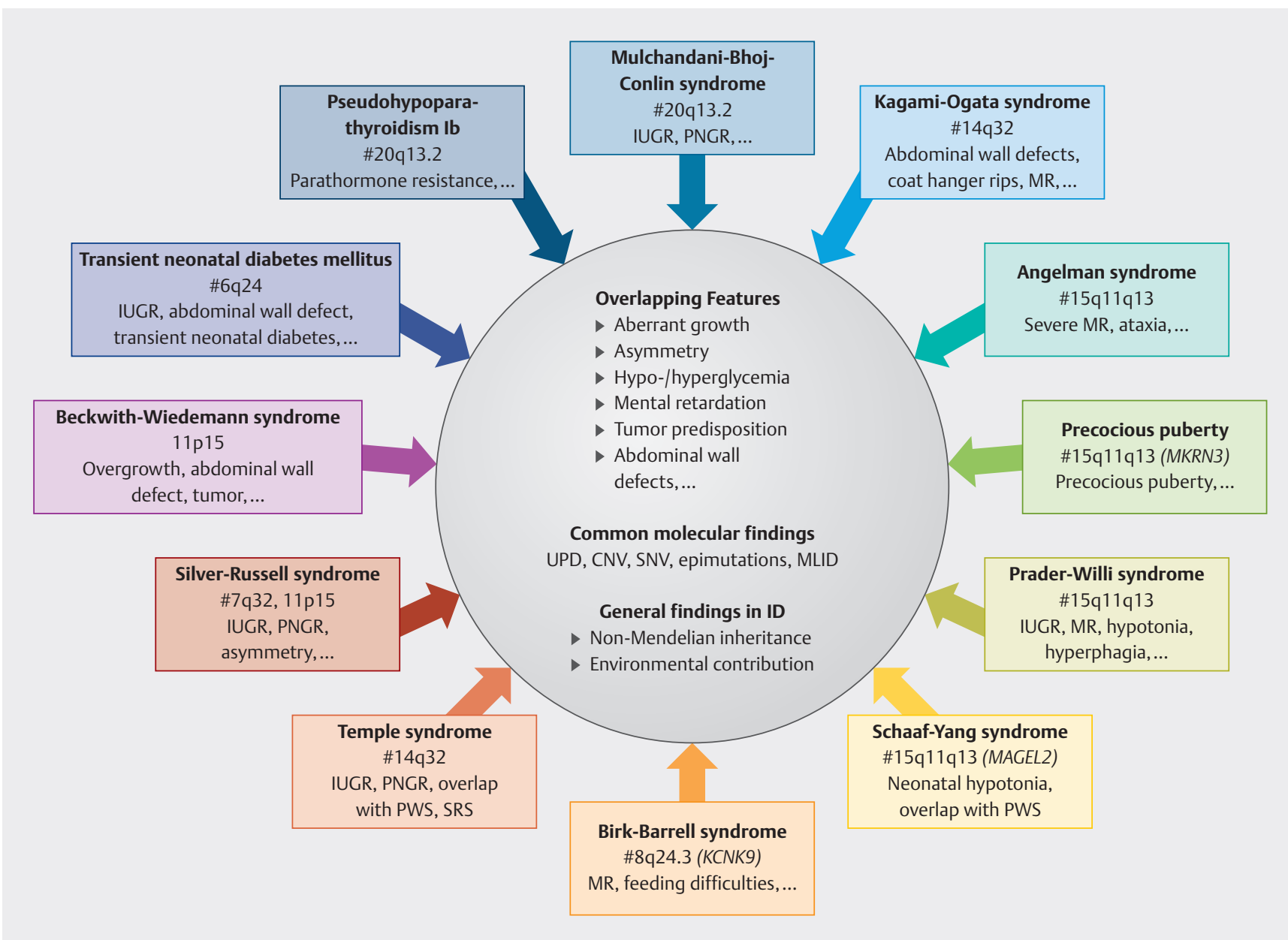

- Fig. 2 Overview on the currently known imprinting disorders and their overlapping features (IUGR: intrauterine growth retardation, PNGR: postnatal growth retardation, MR: mental retardation, UPD: uniparental disomy, CNV: copy number variant, SNV: single nucleotide variant).

Whereas descriptions of factors maintaining the paternal imprints during fertilisation and zygote maturation are rare, in the oocyte the subcortical maternal complex (SCMC) has been identified as a key structure for genomic imprinting ( $>$ Fig. 3 ). The SCMC is a multiprotein complex that mediates oocyte maturation and progress of the early zygote on different levels [25]. Its transcripts are expressed in the oocyte from the maternal genome, and degrade in the early embryonic development. As a result, embryos of female knockout mice lacking some of these SCMC proteins arrest in early cleavage stages (for review: [26, 27]). The function of the SCMC includes the formation and assembly of the meiotic and mitotic spindles as the basis for a proper chromosomal segregation, the rearrangement of oocyte and zygote compartments, regulation of metabolism of RNA expressed from the maternal genome in the oocyte and zygote genome activation, as well as imprinting maintenance. Due to these divers functions of the SCMC proteins it is not surprising that genomic variants in these factors cause a spectrum of reproductive disturbances, ranging from hydatidiform moles (HYDM) and miscarriages to aneuploidy and altered imprinting in the offspring ( $\triangleright$ Table 1 ).

\section{Maternal Effect Variants in SCMC Encoding Genes and Genomic Imprinting}

Genetic variants in SCMC encoding genes exhibit a novel mode of inheritance, as they become functionally relevant only in female carriers. They do not affect the health of the carrier herself, but of her reproductive outcome.

The first maternal effect variants have been reported in families with (recurrent) HYDM and miscarriages 10 years ago, affecting NLRP7 and KHDC3L (C6orf221) [28, 29]. Women suffering from recurrent miscarriages due to HYDM are homozygous or compound heterozygous for mutations in these genes, and an autosomal recessive mode of inheritance has been suggested. It is meanwhile well established to screen women suffering from recurrent HYDM for pathogenic variants in these genes, and oocyte donation has already been shown to be a suitable tool to circumvent the risk of miscarriage [16, 30]. With MEl1, TOP6BL/C11 orf80 and REC114, further genes have recently been suggested to be putatively linked to HYDM [31]. 
-Table 1 Overview on members of the SCMC and associated pregnancy complications.

\begin{tabular}{|c|c|c|c|c|c|c|c|}
\hline Human Gene & $\begin{array}{l}\text { Mouse } \\
\text { Gene }\end{array}$ & Known Functions* & $\begin{array}{l}\text { Effect on fe- } \\
\text { male sterility }\end{array}$ & HYDM & Miscarriages & Aneuploidy & $\begin{array}{l}\text { MLID in } \\
\text { offspring }\end{array}$ \\
\hline $\begin{array}{l}\text { NLRP2 } \\
\text { (NLR Family Pyrin } \\
\text { domain-containing 2) }\end{array}$ & NIrp2 & $\begin{array}{l}\text { - } \text { proper methylation at } \\
\text { imprinted loci } \\
\text { - } \text { spindle assembly }\end{array}$ & & & yes & yes & yes \\
\hline $\begin{array}{l}\text { NLRP5 } \\
\text { (NLR Family Pyrin } \\
\text { domain-containing 5) }\end{array}$ & Mater & $\begin{array}{l}\text { - Interacts with KHDC3L } \\
\text { - Interacts with OOEP/TE6 } \\
\text { - Spindle assembly/position }\end{array}$ & & & yes & & yes \\
\hline $\begin{array}{l}\text { NLRP7** } \\
\text { (NLR Family Pyrin } \\
\text { domain-containing 7) }\end{array}$ & $\begin{array}{l}\text { No ortho- } \\
\text { logue }\end{array}$ & - compensatory to NLRP2 & & yes & yes & yes & yes \\
\hline $\begin{array}{l}\text { OOEP } \\
\text { (Oocyted permitting } \\
\text { embryonic development) }\end{array}$ & Floped & $\begin{array}{l}\text { - Interacts with NLRP5/TLE6 } \\
\text { - Spindle assembly/position }\end{array}$ & & & & & yes \\
\hline $\begin{array}{l}\text { TLE6 } \\
\text { (Transducing-like } \\
\text { enhancer of split 6) }\end{array}$ & Tle6 & $\begin{array}{l}\text { - Interacts with NLRP5/OOEP } \\
\text { - Spindle assembly/position }\end{array}$ & yes & & & & \\
\hline $\begin{array}{l}\text { PADI6 } \\
\text { (Peptidyl arginine } \\
\text { deiminase 6) }\end{array}$ & Padi6 & $\begin{array}{l}\text { - Spindle assembly/position } \\
\text { - Rearrangement of organelles }\end{array}$ & yes & yes & yes & yes & yes \\
\hline $\begin{array}{l}\text { KHDC3L } \\
\text { (KH Domain } \\
\text { containing 3-like } \\
\text { ECTA1, C6ORF221) }\end{array}$ & Filia & $\begin{array}{l}\text { - Interacts with NLRP5 } \\
\text { - Spindle assembly }\end{array}$ & & yes & yes & & yes \\
\hline
\end{tabular}

* Only some physiological functions are listed; ** Human NLRP7 is highly homologous to NLPR2 and its evolutionary origin from this gene has been suggested. HYDM: hydatidiform mole; MLID: multilocus imprinting disturbance

The first evidence for a role of SCMC proteins (i.e. NLRPs [Nucleotide-binding oligomerization domain, Leucine rich Repeat and Pyrin domain containing]) in the maintenance of maternal imprinting marks was obtained from a family with two children suffering from BWS due to LoM of the IC2 in 11p15.5 [32]. Meyer et al. reported for the first time that homozygosity for a NLRP2 frameshift variant in the mothers causes recurrent imprinting disturbances. NLRPs (also called NALPs) are types of NOD-like receptors, and commonly involved in the innated immunity. Autosomaldominant mutations in NLRP3 are responsible for different inborn diseases associated with inflammation (e.g. familial cold autoinflammatory syndrome), whereas NLRP7 variants have first been reported to cause HYDM (see before). NLRPs have first been identified to play a role in innate immunity, but their role for a proper maintenance of imprinting in the oocyte and early embryo is obvious. Up to now, maternal effect variants causing aberrant imprinting marks have been identified in two other members of the NLRP family, NLRP5 and NLRP7[33, 34, 14, 35, 36]. Though the precise functional link between maternal effect variants and disturbed imprinting is currently unknown, the physiological interactions between the different SCMC members and putative compensation mechanisms (i.e. of NLRP2 and NLRP7 in humans) make their implementation in imprinting maintenance plausible ( Fig. 3, - Table 1). NLRP proteins play a key role in inflammation by aggregating components of the inflammasome, and it might be discussed whether the reproductive complications in women carrying genetic SCMC variants might be triggered by inflammation processes.

Though the majority of MLID associated maternal effect variants have been identified in NLRP genes so far, the availability of exome and genome wide NGS-based assays allows the increasing detection of maternal effect variants in other SCMC genes, interacting with NLRP proteins ( $\triangleright$ Table 1 ). In fact, accumulating data on PADI6 variants strongly indicate that PADI6 disturbances also contribute to the clinical spectrum of SCMC-associated pregnancy complications [37, 38, 39], among them MLID [14, 15, 40]. Additionally, the first identification of variants in KHDC3L and OOEP in MLID further confirms that disturbed imprinting belongs to the spectrum of SCMC associated disorders [14, 41].

In fact, HYDM, miscarriages and MLID are obvious features of reproductive failure linked to genetic disturbances of the SCMC, but three reports indicate that chromosomal aberrations should be added to this spectrum: Up to now, aneuploidies have been reported in families with NLRP2, NLRP7 and PADI6 variants [14, 15, 42]. It is currently unclear whether the coincidental occurrence of aneuploidies and maternal effect variants is incidental, or whether it is due to a common mechanism. Due to the central role of SCMC proteins in the formation and positioning of the meiotic/mitotic spindle apparatus a causative link is conceivable (e.g. [41]).

The hypotheses on the functional role of the SCMC and his members in human oocyte maturation and early embryonic development are partially based on the identification of maternal effect 


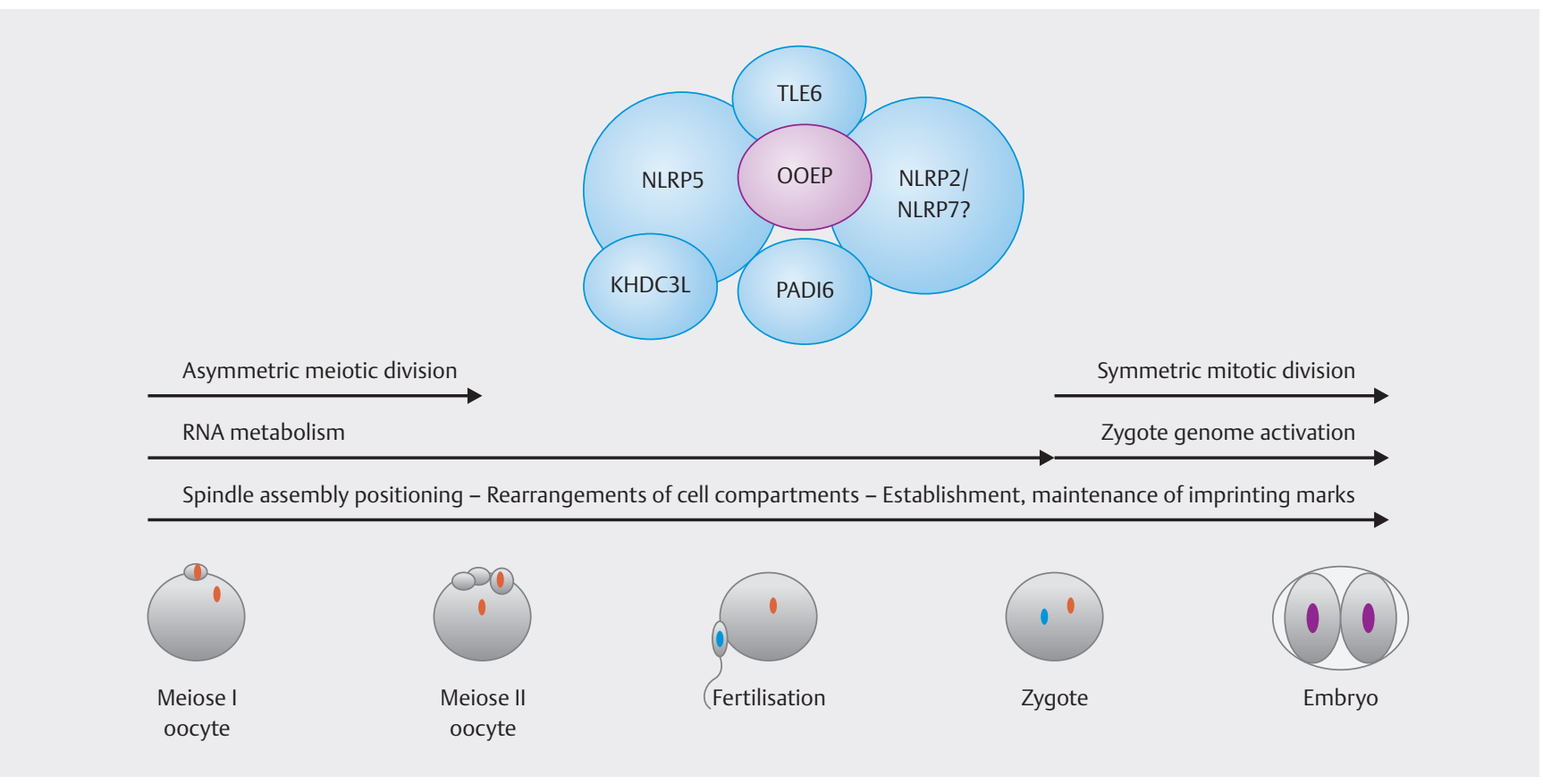

- Fig. 3 Factors of the SCMC and function of the SCMC in oocyte maturation and early zygote.

mutations, but the major insights have been obtained from mouse models. Numerous studies in mouse oocytes and embryos from knock-out mice lines have been published, and excellent reviews on DNA methylation reprogramming in development are available (e.g. [24, 27, 43]). As the detailed description of these studies would go beyond the scope of this paper, the reader is kindly asked to read such overviews.

\section{Maternal Effect Mutations: \\ Translation into Clinical Practice}

Though the functional links between maternal effect variants in SCMC encoding genes and the resulting pregnancy complications is widely unknown, their disease-causing potential is obvious. The features resulting from SCMC gene variants comprise hydatidiform moles/HYDM, recurrent miscarriages, and (multilocus) imprinting disturbances in the offspring. Furthermore, SCMC variants might be associated with numerical chromosomal aberrations.

However, the contribution of single SCMC members is currently unclear, and requires further enlightenment. In fact, maternal effect mutations in KHDCL3 and NLRP7 definitely cause (recurrent) HYDM, and the causative role of NLRP2, NLRP5, NLRP7 and PADI6 for MLID in offspring of female carriers is obvious.

Therefore, in the genetic diagnostic workup in families with fulminant pregnancy failures, the analyses of the aforementioned SCMC genes has to be conducted. With the implementation of comprehensive NGS-based assays (e.g. WES) these factors can be easily targeted in one assay. Additionally, rare genetic variants and even new candidate genes are detectable by NGS approaches, though contribution of these alterations to reproductive failure has to be proved before they are implemented in routine genetic testing. A major prerequisite to determine the clinical relevance of these novel variants and genes is the detailed clinical documentation, including information on family history, infertility, miscarriages, pregnancy complications, and congenital malformations and dysmorphisms in the offspring. The molecular and cytogenetic workup of the POCs might be extremely valuable and helpful to estimate the pathogenic potential of novel variants and factors.

Based on the current data, molecular testing should already now be advised to women

- experiencing multiple miscarriages, among them hydatidiform moles and aneuploidies,

- recurrently delivering offspring with disturbed imprinting,

- with a reproductive and/or family history comprising all these features ( $\triangleright$ Fig. 1).

In case a maternal effect variant in a SCMC encoding gene is detected, the patient should be informed about the following issues:

- The risk of miscarriages and offspring with aberrant imprinting and/or aneuploidy is increased.

- Prenatal testing targeting disturbed imprinting and aneuploidy is principally possible, but prenatal imprinting analysis is not reliable in any case. Even an altered imprinting is detected, this result can hardly be used to predict the phenotype of the offspring (e.g. [33], as only selected tissues are analysed in prenatal context (e.g. amniocytes), and mosaic distribution of aberrant methylation (e.g. variable degree of disturbed imprinting marks in different tissues) is common in imprinting disorders.

- For several imprinting disorders, preterm delivery is a common feature. Additionally, an increased risk for pregnancy-associated hypertension has been reported at least for BWS [23]. Therefore, women with an increased risk for disturbed imprint- 
ing in their offspring due to maternal effect mutations should be closely monitored during pregnancy.

- Oocyte donation has been suggested as therapeutic option and might therefore be discussed with families carrying maternal effect variants obviously affecting the reproduction history $[30,33]$. Of course, the national legal regulations for oocyte donation have to be followed.

- For genetic counselling, it has to be considered that the phenotype only occurs in case women are carriers, thus a variant might be transmitted through the paternal germ line without detection.

\section{Conclusion}

Pathogenic variants affecting the function of SCMC factors in oocyte and early embryo progression cause a broad range of reproductive failures and pregnancy complications. Therefore, the identification of women with molecular alterations in SCMC encoding genes is required as the basis of a personalised reproductive and genetic counselling. The diagnostic application of new genomewide NGS-based techniques allows the comprehensive analysis of these factors, and helps to further decipher these functional links between the factors and their disturbances. A close interdisciplinary collaboration between molecular biologists, human geneticists, bioinformatics scientists, reproduction medicines, gynaecologists and paediatricians is required to further decipher the complex regulation of early embryo development, and to translate the basic research results into clinical practice.

\section{Acknowledgement}

The author is supported by the Deutsche Forschungsgemeinschaft (DFG, EG110/15-1).

\section{Fundings}

EG110/15-1 | Deutsche Forschungsgemeinschaft | http://dx.doi.org/ $10.13039 / 501100001659$

\section{Conflict of Interest}

The authors declare that they have no conflict of interest.

\section{References}

[1] Edmonds DK, Lindsay KS, Miller JF et al. Early embryonic mortality in women. Fertil Steril 1982; 38: 447-453

[2] Choudhury SR, Knapp LA. Human reproductive failure I: immunological factors. Hum Reprod Update 2001; 7: 113-134. doi:10.1093/humupd/7. 2.113

[3] Krausz C, Riera-Escamilla A. Genetics of male infertility. Nat Rev Urol 2018; 15: 369-384. doi:10.1038/s41585-018-0003-3

[4] Yatsenko SA, Rajkovic A. Genetics of human female infertility†. Biol Reprod 2019; 101: 549-566. doi:10.1093/biolre/ioz084
[5] Xavier M], Salas-Huetos A, Oud MS et al. Disease gene discovery in male infertility: past, present and future. Hum Genet 2021; 140: 7-19. doi:10. 1007/s00439-020-02202-x

[6] Robbins SM, Thimm MA, Valle D et al. Genetic diagnosis in first or second trimester pregnancy loss using exome sequencing: a systematic review of human essential genes. J Assist Reprod Genet 2019; 36: 1539-1548. doi:10.1007/s10815-019-01499-6

[7] Papas RS, Kutteh WH. A new algorithm for the evaluation of recurrent pregnancy loss redefining unexplained miscarriage: review of current guidelines. Curr Opin Obstet Gynecol 2020; 32: 371-379. doi:10.1097/ GCO.0000000000000647

[8] Toth B, Wurfel W, Bohlmann M et al. Recurrent Miscarriage: Diagnostic and Therapeutic Procedures. Guideline of the DGGG, OEGGG and SGGG (S2k-Level, AWMF Registry Number 015/050). Geburtsh Frauenheilkd 2018; 78: 364-381. doi:10.1055/a-0586-4568

[9] Page JM, Silver RM. Genetic Causes of Recurrent Pregnancy Loss. Clin Obstet Gynecol 2016; 59: 498-508. doi:10.1097/GRF.0000000000000217

[10] ESHRE Guideline Group on RPL, Bender Atik R, Christiansen OB, Elson J et al. ESHRE guideline: recurrent pregnancy loss. Hum Reprod Open 2018; 2018: hoy004

[11] Barseghyan H, Tang W, Wang RT et al. Next-generation mapping: a novel approach for detection of pathogenic structural variants with a potential utility in clinical diagnosis. Genome Med 2017; 9: 90. doi:10.1186/s1307 3-017-0479-0

[12] Elbracht M, Meyer R, Eggermann T et al. Rational use of genetic tests in internal medicine: Possibilities and limitations of next generation sequencing diagnostics. Internist (Berl) 2018; 59: 756-765. doi:10.1007/s 00108-018-0457-7

[13] Blackburn HL, Schroeder B, Turner C et al. Management of Incidental Findings in the Era of Next-generation Sequencing. Curr Genomics 2015; 16: 159-174. doi:10.2174/1389202916666150317232930

[14] Begemann M, Rezwan Fl, Beygo J et al. Maternal variants in NLRP and other maternal effect proteins are associated with multilocus imprinting disturbance in offspring. J Med Genet 2018; 55: 497-504. doi:10.1136/j medgenet-2017-105190

[15] Eggermann T, Kadgien G, Begemann M et al. Biallelic PADI6 variants cause multilocus imprinting disturbances and miscarriages in the same family. Eur J Hum Genet 2021; 29: 575-580. doi:10.1038/s41431-020-0 0762-0

[16] Elbracht M, Mackay D, Begemann M et al. Disturbed genomic imprinting and its relevance for human reproduction: causes and clinical consequences. Hum Reprod Update 2020; 26: 197-213. doi:10.1093/humup $\mathrm{d} / \mathrm{dmz} 045$

[17] Bilal MY, Katara G, Dambaeva S et al. Clinical molecular genetics evaluation in women with reproductive failures. Am J Reprod Immunol 2020: e13313. doi:10.1111/aji.13313

[18] Eggermann T, Soellner L, Buiting K et al. Mosaicism and uniparental disomy in prenatal diagnosis. Trends Mol Med 2015; 21: 77-87. doi:10.101 6/j.molmed.2014.11.010

[19] Begemann M, Zirn B, Santen G et al. Paternally Inherited IGF2 Mutation and Growth Restriction. N Engl J Med 2015; 373: 349-356. doi:10.1056/ NEJMoa1415227

[20] Soellner L, Begemann M, Mackay D] et al. Recent Advances in Imprinting Disorders. Clin Genet 2017; 91: 3-13. doi:10.1111/cge.12827

[21] Sanchez-Delgado M, Riccio A, Eggermann T et al. Causes and Consequences of Multi-Locus Imprinting Disturbances in Humans. Trends Genet 2016; 32: 444-455. doi:10.1016/j.tig.2016.05.001

[22] Mackay DJG, Temple IK. Human imprinting disorders: Principles, practice, problems and progress. Eur J Med Genet 2017; 60: 618-626. doi:10.101 6/j.ejmg.2017.08.014

[23] Kagan KO, Berg C, Dufke A et al. Novel fetal and maternal sonographic findings in confirmed cases of Beckwith-Wiedemann syndrome. Prenat Diagn 2015; 35: 394-399. doi:10.1002/pd.4555 
[24] Monk D, Mackay DJG, Eggermann T et al. Genomic imprinting disorders: lessons on how genome, epigenome and environment interact. Nat Rev Genet 2019; 20: 235-248. doi:10.1038/s41576-018-0092-0

[25] Lu X, Gao Z, Qin D et al. A Maternal Functional Module in the Mammalian Oocyte-To-Embryo Transition. Trends Mol Med 2017; 23: 1014-1023. doi:10.1016/j.molmed.2017.09.004

[26] Bebbere D, Masala L, Albertini DF et al. The subcortical maternal complex: multiple functions for one biological structure? J Assist Reprod Genet 2016; 33: 1431-1438. doi:10.1007/s10815-016-0788-z

[27] Monk D, Sanchez-Delgado M, Fisher R. NLRPs, the subcortical maternal complex and genomic imprinting. Reproduction 2017; 154: R161-R170. doi:10.1530/REP-17-0465

[28] Murdoch S, Djuric U, Mazhar B et al. Mutations in NALP7 cause recurrent hydatidiform moles and reproductive wastage in humans. Nat Genet 2006; 38: 300-302. doi:10.1038/ng1740

[29] Parry DA, Logan CV, Hayward BE et al. Mutations causing familial biparental hydatidiform mole implicate c6orf221 as a possible regulator of genomic imprinting in the human oocyte. Am J Hum Genet 2011; 89: 451-458. doi:10.1016/j.ajhg.2011.08.002

[30] Akoury E, Gupta N, Bagga R et al. Live births in women with recurrent hydatidiform mole and two NLRP7 mutations. Reprod Biomed Online 2015; 31: 120-124. doi:10.1016/j.rbmo.2015.03.011

[31] Nguyen NMP, Ge Z], Reddy R et al. Causative Mutations and Mechanism of Androgenetic Hydatidiform Moles. Am J Hum Genet 2018; 103: 740751. doi:10.1016/j.ajhg.2018.10.007

[32] Meyer E, Lim D, Pasha S et al. Germline mutation in NLRP2 (NALP2) in a familial imprinting disorder (Beckwith-Wiedemann Syndrome). PLoS Genet 2009; 5: e1000423. doi:10.1371/journal.pgen.1000423

[33] Soellner L, Begemann M, Degenhardt F et al. Maternal heterozygous NLRP7 variant results in recurrent reproductive failure and imprinting disturbances in the offspring. Eur J Hum Genet 2017; 25: 924-929. doi:10.1 038/ejhg.2017.94

[34] Docherty LE, Rezwan FI, Poole RL et al. Mutations in NLRP5 are associated with reproductive wastage and multilocus imprinting disorders in humans. Nat Commun 2015; 6: 8086. doi:10.1038/ncomms9086
[35] Sparago A, Verma A, Patricelli MG et al. The phenotypic variations of multi-locus imprinting disturbances associated with maternal-effect variants of NLRP5 range from overt imprinting disorder to apparently healthy phenotype. Clin Epigenetics 2019; 11: 190. doi:10.1186/s13148019-0760-8

[36] Soellner L, Kraft F, Sauer S et al. Search for cis-acting factors and maternal effect variants in Silver-Russell patients with ICR1 hypomethylation and their mothers. Eur J Hum Genet 2019; 27: 42-48. doi:10.1038/s41 431-018-0269-1

[37] Qian J, Nguyen NMP, Rezaei M et al. Biallelic PADI6 variants linking infertility, miscarriages, and hydatidiform moles. Eur J Hum Genet 2018; 26 : 1007-1013. doi:10.1038/s41431-018-0141-3

[38] Xu Y, Shi Y, Fu J et al. Mutations in PADI6 Cause Female Infertility Characterized by Early Embryonic Arrest. Am J Hum Genet 2016; 99: 744-752. doi:10.1016/j.ajhg.2016.06.024

[39] Zheng W, Chen L, Dai J et al. New biallelic mutations in PADI6 cause recurrent preimplantation embryonic arrest characterized by direct cleavage. J Assist Reprod Genet 2020; 37: 205-212. doi:10.1007/s10815-0 19-01606-7

[40] Cubellis MV, Pignata L, Ve, rma A et al. Loss-of-function maternal-effect mutations of PADI6 are associated with familial and sporadic BeckwithWiedemann syndrome with multi-locus imprinting disturbance. Clin Epigenetics 2020; 12: 139. doi:10.1186/s13148-020-00925-2

[41] Demond $\mathrm{H}$, Anvar Z, Jahromi BN et al. A KHDC3L mutation resulting in recurrent hydatidiform mole causes genome-wide DNA methylation loss in oocytes and persistent imprinting defects post-fertilisation. Genome Med 2019; 11: 84. doi:10.1186/s13073-019-0694-y

[42] Deveault C, Qian JH, Chebaro W et al. NLRP7 mutations in women with diploid androgenetic and triploid moles: a proposed mechanism for mole formation. Hum Mol Genet 2009; 18: 888-897

[43] Greenberg MVC, Bourc'his D. The diverse roles of DNA methylation in mammalian development and disease. Nat Rev Mol Cell Biol 2019; 20: 590-607. doi:10.1038/s41580-019-0159-6 